\title{
DNA barcoding of the Indian blackbuck (Antilope cervicapra) and their correlation with other closely related species
}

\author{
Vikas Kumar ${ }^{1}$, Neelkamal Sharma ${ }^{1 *}$ and Arun Sharma ${ }^{2}$
}

\begin{abstract}
Background: Sequence divergence in mitochondrial cytochrome c oxidase subunit I genes (COI) has been used as an efficient forensic tool in solving wildlife-related problems and also be used in molecular taxonomy for species identification.

Methods: This study presents the DNA barcode sequences of the Blackbuck (Antilope cervicapra) from Haryana, India. A dataset of 43 partial $\mathrm{COI}$ sequences of 13 species belonging to 4 genus of Antilopinae sub- family were used for molecular analysis and to construct the phylogenetic tree to elucidate the species diversity among sub-family Anitlopinae. The data comprised of generated sequences of the Blackbuck $(n=22)$ and with additional COI sequences of the related species $(n=21)$ showing maximum homology with Blackbuck COI sequence were downloaded from NCBI-GenBank for wide coverage of inter and intra-specific nucleotide diversity.
\end{abstract}

Results: Phylogenetic analysis demonstrated that the studied COI region provided accurate species clustering showing their importance in wildlife species identification. The intra-specific sequence divergence of all the studied Antilopinae species was observed $0.47 \%(<1 \%)$. Specifically in the studied genus- Antilope, it was observed $0.3 \%$. Whereas the interspecific divergence was in the range of $0.3-12.6 \%$ among 13 species from 4 genus. The highest interspecific divergence was observed among Antilope cervicapra and Gazella erlangeri (12.6\%).

Conclusion: The developed species-specific barcoding (COI) sequence of Indian Blackbuck from Haryana, India, demonstrated their high potential to identify Blackbuck from their sympatric species in wildlife-related crimes and in conservation activities. Published Barcode sequences in the both database serve as a wildlife forensic tool to solve Blackbuck related crimes. This study supports the credibility of DNA Barcoding in forensic investigation and wildlife conservation and also emphasized the need for species barcode database from each country to assist in solving wildlife related offenses.

Keywords: Sequence divergence, DNA barcode, Forensic, Wildlife-related problems, COI, Antilope cervicapra

\section{Background}

India is known as a mega biodiversity nation for its abundant wild flora and fauna, but the country is not untouched by the problem of biodiversity loss and the need to implement conservation efforts to protect its vulnerable biodiversity. Although Haryana, a state in the northern part of India, is deficient in natural forests, but it has a rich biodiversity of some wild animals, especially Blackbuck antelopes (Antilope cervicapra). The Blackbuck is native to

\footnotetext{
*Correspondence: neelforensics@gmail.com

${ }^{1}$ Department of Genetics, Maharshi Dayanand University, Rohtak, Haryana, India

Full list of author information is available at the end of the article
}

the Indian subcontinent, and it is protected as a scheduled-I animal under the 1972 Wildlife Protection Act, enacted by the Indian government (Kumar et al. 2017). Once, Blackbuck antelopes were abundant and ranged throughout Haryana, but now their population has been marginalized and confined to the southwestern part of Haryana, and are nearly to extinct in the rest of the state due to increases in wildlife poaching, infrastructure development, and biotic interference. The alarming rate of the population depletion of the Blackbuck has brought it to the verge of extinction, and this is a matter of concern for the state.

Forensic approaches have been adopted to identify wildlife animal species in need of conservation and to 
prevent their fraudulent misidentification, especially from samples of animal residues and the products made from processing their parts (Iyengar 2014; Tobe \& Linacre 2010; Hsieh et al. 2011; Ogden et al. 2009). Advances in molecular science have launched a new era in the taxonomy of species identification, even with a bit of biological sample which, sometimes, is not possible to identify using conventional morphological methods. DNA barcoding is a molecular taxonomic idea initiated by Hebert et al. (2003) to transform conventional taxonomy by digitizing the identity of a given species (Hebert et al. 2003). Thus, a DNA barcode is a standardized approach used to identify species from partial sequences of DNA (Hebert and Gregory, 2005; Kumar et al. 2012). This technique uses the mitochondrial region of cytochrome $\mathrm{C}$ oxidase subunit I (COI) to provide a strong species-level resolution for diverse wildlife (Linacre \& Tobe 2011). The DNA barcode region contains highly conserved sites for primer binding, and it can be used to show interspecific variations (Ferri et al. 2009; Eaton et al. 2010). This method has been attracting international attention due to its significant role in advancing the taxonomy of life forms and their forensic implications.

The successful amplification for the DNA barcode region requires cross-species primers, which are the universal primers designed to amplify homologous sequences in other closely related species (Housley et al. 2006; Ghosh et al., 2013; Lucio et al. 2011). In the present research study, we selected the universal primers of the COI gene by checking their feasibility and specificity to develop a species-specific DNA sequence as a barcode sequence for the Blackbuck species. The first specific objective of the present study was to develop and enrich the DNA barcode data of the Blackbuck from Haryana, India, found in the Barcode of Life Database (BOLD) and National Center for Biotechnology Information (NCBI) database. Secondly, we evaluated the ability of the COI barcoding gene to identify the Blackbuck species from its sympatric species and to elucidate its species diversity.

\section{Material and methods Sample collection}

Around 25 blood and tissue samples of the Blackbuck animal were collected from different part from Haryana, India. Blood samples were collected during a veterinary checkup and tissue samples from Pathology Department, LUVAS University, Hisar, during the postmortem analysis, with the permission of the Wildlife Department of Haryana, in the presence of wildlife staff and veterinary doctors. Blood samples were taken and preserved in EDTA tubes and finally stored at $4{ }^{\circ} \mathrm{C}$ and tissue samples were preserved at $-80{ }^{\circ} \mathrm{C}$. Permission for the sample collection for the scientific research is granted by the National (MoEF\&CC) and State government body vide letter no 1-56/2016 and WL-87/11-04-16 respectively.

\section{Primer selection}

A universal set of Primer was selected for this study from the primer database available in BOLD system to target the barcode COI sequence of the Antilope cervicapra. In details, of primer were VF1 (5'-ttctcaaccaaccacaaagacattgg-3') and VR1 (5'-tagacttctgggtggccaaagaatca-3').

\section{DNA extraction, PCR amplification, and sequencing}

A good quality of 22 samples of DNA (50 ng) were extracted using DNeasy blood and tissue Kit (Qiagen, Valencia, CA, USA) following manufacturer's instruction. All PCR reaction for the amplifications of the COI region were carried out using 1X PCR Buffer, $2.5 \mathrm{mM} \mathrm{MgCl} 2,0.4 \mathrm{mM}$ of each of dNTPs, $10 \mathrm{pM}$ each of forward and reverse primers and one units of Taq polymerase in a $50 \mu$ final reaction volume. The amplification were carried out as follow: initial denaturation at $95{ }^{\circ} \mathrm{C}$ for $5 \mathrm{~min}$, followed by 35 cycles at $95{ }^{\circ} \mathrm{C}$ for $45 \mathrm{~s}, 54{ }^{\circ} \mathrm{C}$ for $45 \mathrm{~s}$ and $72{ }^{\circ} \mathrm{C}$ for $1 \mathrm{~min}$, and a final elongation for $10 \mathrm{~min}$ at $72{ }^{\circ} \mathrm{C}$ in a Takara PCR System 9700 . The Amplification results of PCR products were checked by electrophoresis in $1.2 \%$ agarose gel stained with ethidium bromide and visualized in Gel-doc system.

The successful amplified PCR products were purified using QIAquick PCR Purification Kit Qiagen. The purified PCR products were sequenced (Eurofins Genomics India Pvt. Ltd) on both strands. The obtained chromatograms were analyzed and manually edited in the Chromas 2.4 software (Technelysium Pty Ltd., South Brisbane, Australia). The terminal ends of the sequence were trimmed to obtain the consensus sequences of $637 \mathrm{bp}$. Polymorphic bases were checked using the original chromatograms in MEGA v7 (Kumar et al. 2016).

\section{Barcode tree analysis}

The DNA barcoding primers successfully amplified the desired sequence of the COI region of Blackbuck yielding an approximately $640-720$ bp size product. The results were blasted for similarity search against nonredundant sequence database showing high degree of similarity (99-100\%) with the corresponding sequences of Blackbuck both in BOLD and GenBank database, confirmed the successful amplification and could be used as a DNA barcode for species identification (Johnson et al. 2008; Dalton \& Kotze 2011).

A dataset of 43 sequences were used for molecular analysis and to construct the Neighbour-Joining phylogenetic tree. The data comprised of generated sequences of the Blackbuck $(n=22)$ and with additional COI sequences of the related species $(n=21)$ showing maximum homology were used and downloaded from NCBI-GenBank for wide coverage of inter and intra-specific nucleotide diversity (Table 1). From the developed sequences of this study, those sequences showing intraspecific variation were accepted by both NCBI-GenBank and BOLD and are 
Table 1 Showing partial COI sequence of mtDNA used in this study from NCBI-GenBank

\begin{tabular}{|c|c|c|c|}
\hline $\begin{array}{l}\text { Species } \\
\text { Name }\end{array}$ & Genus & $\begin{array}{l}\text { Scientific } \\
\text { name }\end{array}$ & GenBank Accession no. \\
\hline Blackbuck & Antilope & $\begin{array}{l}\text { Antilope } \\
\text { cervicapra }\end{array}$ & $\begin{array}{l}\text { MF102041.1* MF102040.1* } \\
\text { MF102039.1* MF102038.1* } \\
\text { MF102037.1* MF102036.1* } \\
\text { MF102035.1* MF102034.1* } \\
\text { MF102033.1* MF102032.1* } \\
\text { MF102031.1* KX524519.1* } \\
\text { KT372100.1, JN632598.1 }\end{array}$ \\
\hline $\begin{array}{l}\text { Goitered } \\
\text { gazelle or } \\
\text { Black-tailed } \\
\text { gazelle }\end{array}$ & Gazella & $\begin{array}{l}\text { Gazella } \\
\text { subgutturosa }\end{array}$ & $\begin{array}{l}\text { JN632643.1, JN632644.1, } \\
\text { KC679019.1, KX859267.1, } \\
\text { KX859293.1, KC679021.1, } \\
\text { KU527897.1, }\end{array}$ \\
\hline $\begin{array}{l}\text { Red-fronted } \\
\text { gazelle }\end{array}$ & Eudorcus & $\begin{array}{l}\text { Eudorcas } \\
\text { rufifrons }\end{array}$ & JN632633.1, JN632634.1 \\
\hline $\begin{array}{l}\text { Dorcas or } \\
\text { Ariel gazelle }\end{array}$ & Gazella & $\begin{array}{l}\text { Gazella } \\
\text { dorcas }\end{array}$ & JN632638.1, JN632637.1 \\
\hline Rhim gazelle & Gazella & $\begin{array}{l}\text { Gazella } \\
\text { leptoceros }\end{array}$ & JN632641.1 \\
\hline Mountain gazelle & Gazella & $\begin{array}{l}\text { Gazella } \\
\text { gazella }\end{array}$ & JN632640.1 \\
\hline Cuvier's gazelle & Gazella & $\begin{array}{l}\text { Gazella } \\
\text { cuvieri }\end{array}$ & JN632636.1 \\
\hline Speke's gazelle & Gazella & Gazella spekei & JN632642.1 \\
\hline Neumann's gazelle & Gazella & $\begin{array}{l}\text { Gazella } \\
\text { erlangeri }\end{array}$ & JN632639.1 \\
\hline Abyssinian mohr & Nanger & $\begin{array}{l}\text { Nanger } \\
\text { soemmerringii }\end{array}$ & JN632667.1 \\
\hline Grant's gazelle & Nanger & Nanger granti & JN632666.1 \\
\hline Dama gazelle & Nanger & Nanger dama & JN632665.1 \\
\hline
\end{tabular}

*Showing the submitted sequence in NCBI-GenBank database from this study

published in their database. All the 43 sequences representing 13 species from 4 genera of Antilopinae subfamily, were aligned in MUSSCLE program in MEGA v7 software to yield an equal length of 636 bp with no gaps and no indels. MEGA7 software was used to calculate nucleotide diversity and to construct a phylogenetic trees based on Neighbour-joining method incorporated with Kimura 2 parameter (K2P) model (Kumar et al. 2016). Bootstrap values (1000 replicates) for the internal topology were assessed using Giraffa camelopardalis (NCBI accession no. AP003424.1) as an out-group animal to root the phylogenetic tree. In addition, the species identification were also performed in the BOLD search engine and phylogenetic cluster was assessed with the closest matches with using BINs (Barcode Index Number system) assigned by BOLD. BIN is an online platform of the BOLD system that cluster barcode sequences algorithmically to creating a web page for each cluster.

\section{Database submission}

The generated barcode sequences were submitted to BOLD and the NCBI-GenBank database under the project: "DNA Barcoding of Blackbuck, from Haryana, India". The BOLD-IDs and the NCBI Accession No. of the submitted sequence are shown in Table 2. The Supporting Information files of the submitted sequences are available for each record in the Public Data Portal in the BOLD system, with all relevant information, i.e., specimen information, collection date, collector name, specimen images, primer sequences, global positioning system (GPS) coordinates, and trace files for all the specimen collection localities.

\section{Utility of the blackbuck DNA barcodes}

To solve crimes related to Blackbuck wildlife poaching around the world, the utility of these DNA barcodes will play an important role in the wildlife forensics because they provide a reliable and cost-efficient tool for species identification. Although identification through BOLD and the NCBI-GenBank shows 99-100\% matching with Antilope cervicapra sequences, the low number of sequence availability reflects a serious limitation in the database-based identity. Prior to this study, only four or five COI sequences were available in the NCBI-GenBank, and only one submission was available in the Public Data Portal of the COI record in the BOLD system. After submitting the sequences to both databases, a comparatively rich database is now available for Blackbuck, showing its high potential for use in wildlife forensic investigation; this will further help conserve this species.

\section{Results}

The Antilope cervicapra DNA sequences provide 100\% support for the clade in the phylogenetic tree, showing a strong species distinction with other species related to Antilopinae. This implies that four genera were clustered in the appropriate branch (Fig. 1). The NJ-phylogenetic tree were strongly supported the genera and subfamily relationship with high bootstrap values: $100 \%$ for genus Antilope (Blackbuck or Antilope cervicapra), and genus Eudorcas (Eudorcus rufifrons), $99 \%$ and $98 \%$ for genus Nanger (Nanger dama, Nager granti, Nanger soemmerringii) and genus Gazella (Gazella subgutturosa, Eudorcas rufifrons, Gazella dorcas, Gazella leptoceros, Gazella cuvieri, Gazella spekei, Gazella erlangeri) respectively. The phylogenetic tree was also generated through BOLD, showing a 99.37\%

Table 2 Showing submitted list of DNA Barcoding Sequences of Antilope cervicapra in BOLD and NCBI BOLD database with BOLD IDs and Accession No respectively

\begin{tabular}{ll}
\hline BOLD IDs & VDBAC013-17 VDBAC012-17, VDBAC011-17, \\
& VDBAC010-17, VDBAC009-17, VDBAC008-17, \\
& VDBAC007-17, VDBAC006-17, VDBAC005-17, \\
& VDBAC004-17, VDBAC003-17. \\
NCBI & MF102041.1, MF102040.1, MF102039.1, MF102038.1, \\
Accession No & MF102037.1, MF102036.1, MF102035.1, MF102034.1, \\
& MF102033.1, MF102032.1, MF102031.1. \\
\hline
\end{tabular}




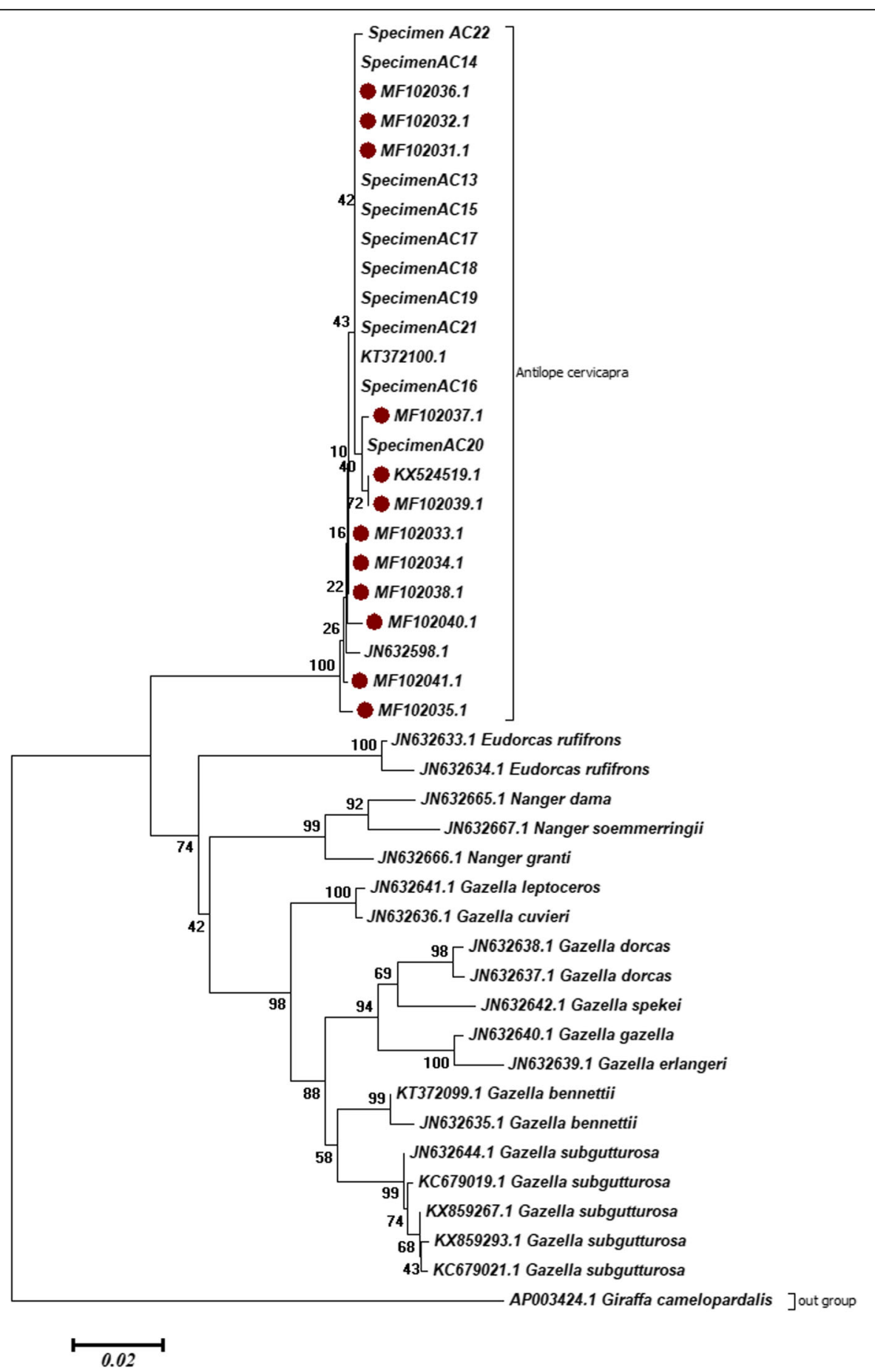

Fig. $1 \mathrm{NJ}$-Phylogenetic tree (K2P) inferred from 636 base-pair 43 partial COI sequences for 13 species belonging to 4 genus of Antilopinae sub-family. Bootstrap values are shown above the species nodes and for higher taxonomic node. Giraffa camelopardalis was used as an out-group animal to root the phylogenetic tree

match with the Antilope cervicapra sequence. However, only one COI sequence was available for identification, thus demonstrating the limitation of this study. After the sequences were submitted, a relatively rich database is now available for comparison. This demonstrates the utility of this study (Fig. 2).

The generated sequences of the study animal $(n=22)$ and the downloaded sequences of the related species $(n=21)$ 


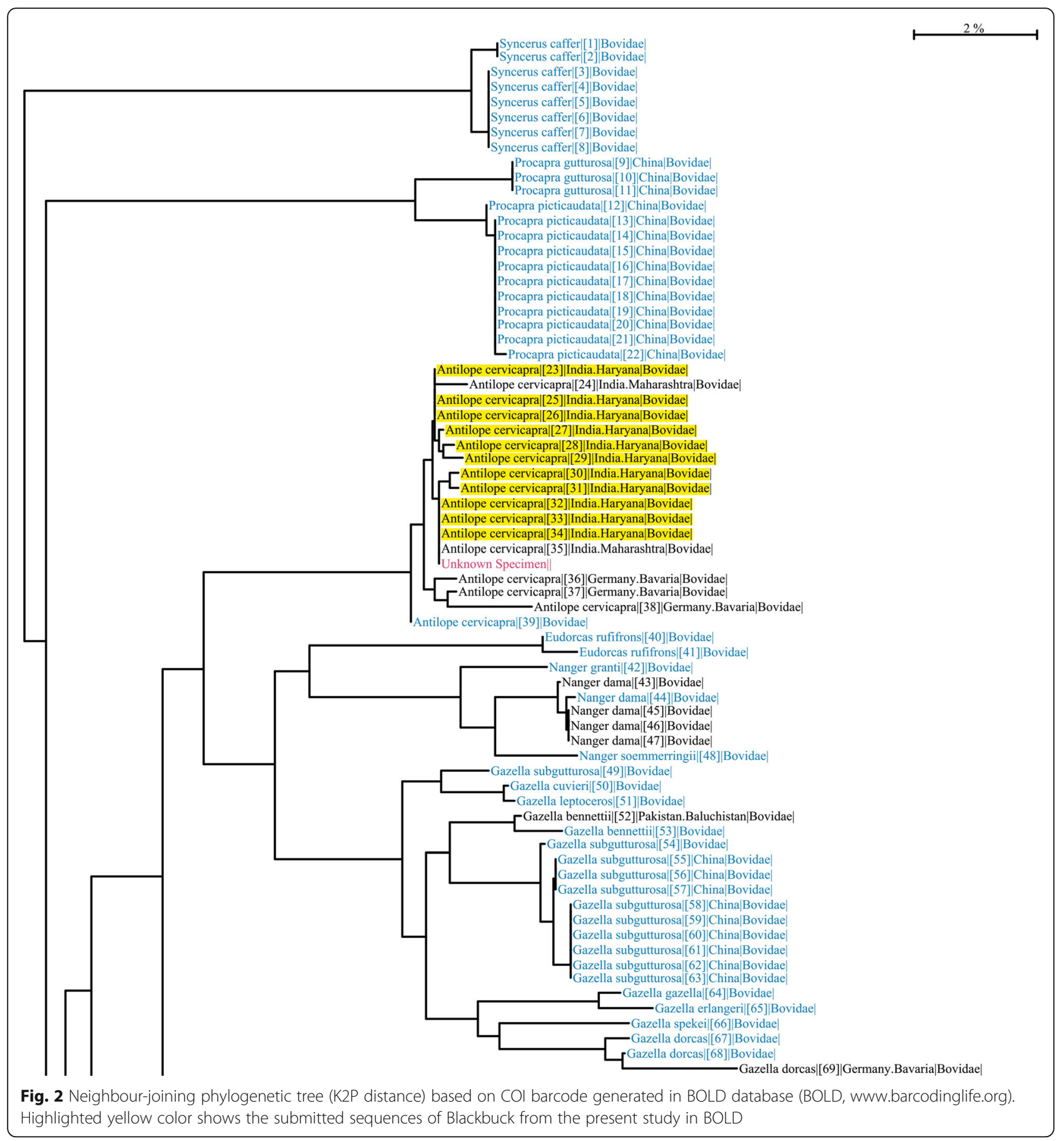

from the GenBank were aligned to yield an equal length of $636 \mathrm{bp}$ without gaps and indels. The results revealed that the 637 bp region within Antilope cervicapra $(n=24)$ had 11variable sites, 625 invariable or conserved sites, 6 Singleton variable sites and 5 parsimony informative sites. Whereas interspecific $(n=43)$ results showing that $636 \mathrm{bp}$ COI sequences had 141 polymorphic sites, 495 monomorphic sites, 23 Singleton variable sites and 118 positions parsimony informative sites. The average of nucleotide composition in the $636 \mathrm{bp}$ partial COI region of 13 Antilopinae species representing 4 genera were: $\mathrm{T}$ (30.4\%) C (26.3\%) A (27.1\%), and G (16.2\%). This is the consent with the fact that the nucleotide $\mathrm{G}$ frequency is lowest amongst all the four nucleotide bases in most of the mammalian species (Lin et al., 1999). Table 3 showing the intraspecific and interspecific genetic distance matrix. Low intraspecific nucleotide diversity was observed within subfamily Antilopinae with an average of $0.47 \%(<1 \%)$. 
Table 3 Pairwise genetic distance using the K2P distance model between 13 Antilopinae species (below diagonal) and mean genetic distance within species represented with two or more specimens (bold numbers on diagonal)

\begin{tabular}{|c|c|c|c|c|c|c|c|c|c|c|c|c|c|}
\hline & 1 & 2 & 3 & 4 & 5 & 6 & 7 & 8 & 9 & 10 & 11 & 12 & 13 \\
\hline 1 & 0.003 & & & & & & & & & & & & \\
\hline 2 & 0.101 & 0.008 & & & & & & & & & & & \\
\hline 3 & 0.104 & 0.084 & $n / c$ & & & & & & & & & & \\
\hline 4 & 0.113 & 0.092 & 0.026 & $n / c$ & & & & & & & & & \\
\hline 5 & 0.094 & 0.082 & 0.026 & 0.040 & $n / c$ & & & & & & & & \\
\hline 6 & 0.092 & 0.088 & 0.087 & 0.085 & 0.087 & $n / c$ & & & & & & & \\
\hline 7 & 0.092 & 0.088 & 0.083 & 0.081 & 0.083 & 0.003 & $n / c$ & & & & & & \\
\hline 8 & 0.115 & 0.110 & 0.092 & 0.089 & 0.096 & 0.052 & 0.052 & 0.005 & & & & & \\
\hline 9 & 0.118 & 0.113 & 0.101 & 0.103 & 0.101 & 0.052 & 0.052 & 0.032 & $n / c$ & & & & \\
\hline 10 & 0.113 & 0.100 & 0.085 & 0.086 & 0.093 & 0.060 & 0.060 & 0.042 & 0.042 & $n / c$ & & & \\
\hline 11 & 0.126 & 0.108 & 0.088 & 0.086 & 0.097 & 0.060 & 0.060 & 0.044 & 0.045 & 0.013 & $n / c$ & & \\
\hline 12 & 0.100 & 0.095 & 0.084 & 0.082 & 0.084 & 0.043 & 0.043 & 0.049 & 0.052 & 0.053 & 0.057 & 0.005 & \\
\hline 13 & 0.107 & 0.090 & 0.072 & 0.066 & 0.071 & 0.047 & 0.043 & 0.049 & 0.048 & 0.050 & 0.053 & 0.032 & 0.003 \\
\hline
\end{tabular}

[1] Antilope_cervicapra, [2] [Eudorcas_rufifrons] [3] Nanger_dama [4] Nanger soemmerringii [5] Nanger_granti [6] Gazella_leptoceros [7] Gazella_cuvieri [8] Gazella_dorcas [9] Gazella_spekei [10] Gazella_gazella [11] Gazella_erlangeri [12] Gazella_bennettii [13] Gazella_subgutturosa

The mean Intra-specific distance was observed in Antilope cervicapra species $(0.3 \%)$ and in Gazella_subgutturosa (0.3\%). The interspecific K2P distance was observed with an average of $6.6 \%$ ranged from $0.3 \%$ to $12.6 \%$ (Table 3 ) The lowest interspecies divergence was observed among Gazella_leptoceros and Gazella_cuvieri (0.3\%) and while the highest interspecific divergence observed in between Antiolpe_cervicapra and Gazella_erlangeri (12.6\%) followed by Antilope_cervicapra and Gazella_spekei (11.8\%).

\section{Discussion and conclusion}

This study showed strong ability of the COI barcoding gene to discriminate the Blackbuck (Antilope cervicapra) with their sympatric species. This study showed that, the intraspecific diversity among 4 genera of sub-family Antilopinae was observed with an average $<1 \%$ and specifically for the studied genus Antilope it was observed 0.3\%. Such a low level intraspecific divergence observed in this study conforms to among other previous COI based studies such as in Tanzanian antelopes (0.2\%)(Bitanyi et al. 2011), Suidae (0.32\%)(Ahanthem et al. 2013), $0.62 \%$ in Bovidae species ((Cai et al. 2011) $0.60 \%$ in Neotropical bats (Clare et al. 2007), $1.1 \%$ in primates (Lorenz et al. 2005), in Birds $(<1 \%)$ (Hebert et al.; 2004), 0.2-0.3\% in fish (Lakra et al. 2009, Hubert et al. 2008), and $1 \%$ in small mammal communities (Borisenko et al. 2008).

The interspecific diversity observed in this study ranged $0.3 \%$ to $12.7 \%$, correspond well with other COI based previous research such as in Tanzanian Antelopes (6.3\% to $22 \%$ ) (Bitanyi et al. 2011) Suidae family (9.9\% to 14\%) (Ahanthem et al. 2013), Bovidae species (mean 12.44\%); Cai et al. 2011) Neotropical bats (mean 7.8\%)
(Clare et al. 2007), Fish (2.5\%-5.9\%) Lakra et al. 2009; Hubert et al. 2008).

The phylogenetic tree clades gave the same results as those obtained from measuring the intra- and interspecific divergences with strong bootstrap values. The same species sequences were clade together with low divergence ( $100 \%$ bootstrap supports), and closely related species from the same sub-family and genus were clearly separated in the study. The phylogenetic analysis of this study supports other cladistics studies conducted on antelopes and Bovidae using barcoding COI genes (Bitanyi et al. 2011; Cai et al. 2011).

In summary, this present study developed a speciesspecific barcoding (COI) sequence for Indian Blackbuck (Antilope cervicapra) from Haryana, India. It demonstrated a high potential to identify Blackbuck antelopes from their sympatric species in wildlife-related (poaching) crimes and in conservation activities. Published barcode sequences in both NCBI and BOLD databases serve as a wildlife forensic tool that can be used to solve Blackbuck-related crimes. The study's results reaffirmed the significance of the DNA barcode gene in wildlife forensics; the findings can be used to discriminate species within the Bovidae family as well as other animals that have been recognized through prior taxonomic work.

\section{Acknowledgements}

Special thanks to all the staff of Wildlife Department of Haryana and Pathology department, LUVAS University Hisar, India for their valuable support in sample collection. We also thankful to the Ministry of Environment \& climate changes (MOEF\&CC), government of India for granting permission for this research work. A sincere thanks to University Grant Commission for providing Junior Research Fellowship, the financial support is highly acknowledged. 


\section{Funding}

The research work was supported by the Department of Genetics, Maharshi Dayanand University, Rohtak, Haryana (India).

\section{Availability of data and materials}

All the data and material are publically available in NCBI GenBank and Barcode of Life database (BOLD) and their respective accession number and BOLD IDs is given in the manuscript.

\section{Authors' contributions}

VK Work plan, sample collection and analysis, data interpretation and manuscript writing. Dr. NS Work plan, standardization, data interpretation, manuscript writing and proof reading. Dr. AS Data interpretation and proof reading. All authors read and approved the final manuscript.

\section{Ethics approval and consent to participate}

This research work was approved by Institutional Animal Ethics Committee (IAEC) vide letter no 151-67/30-03-2015. Permission for the sample collection for this scientific research is granted by the Ministry of Environment \& climate changes (MoEF\&CC) government of India and state Forest \& Wildlife department Haryana vide letter no 1-56/2016 and WL-87/11-04-16 respectively.

\section{Consent for publication}

Not applicable.

\section{Competing interests}

The authors declare that they have no competing interests.

\section{Publisher's Note}

Springer Nature remains neutral with regard to jurisdictional claims in published maps and institutional affiliations.

\section{Author details}

${ }^{1}$ Department of Genetics, Maharshi Dayanand University, Rohtak, Haryana India. ${ }^{2}$ State Forensic Science Laboratory, Himachal Pradesh, Shimla Hills, Junga, India.

Received: 30 October 2017 Accepted: 15 December 2017

Published online: 28 December 2017

\section{References}

Ahanthem M, KSH MD, Ghosh SK (2013) DNA barcoding of indigenous pig in northeast India. Indian J Anim Sci 83(4):428-430

Bitanyi S, Bjornstad G, Ernest EM, Nesje M, Kusiluka LJ, Keyyu JD, Mdegela RH, Roed KH (2011) DNA Barcoding: species identification of Tanzanian antelopes using DNA barcoding. Molecular Ecol Res 11:442-449

Borisenko AV, Lim BK, Ivanova NV, Hanner RH, Hebert PDN (2008) DNA barcoding in surveys of small mammal communities: a field study in Suriname. Mol Ecol Resour 8(3):471-479

Cai YS, Zhang L, Shen FJ, Zhang WP, Hou R, Yue BS, Li J, Zhang ZH (2011) DNA barcoding of 18 species of Bovidae. Chin Sci Bull 56(2):164-168

Clare EL, Lim BK, Engstrom MD, Eger JL, Hebert PDN (2007)DNA barcoding of Neotropical bats: species identification and discovery within Guyana. Mol ecol notes 7:184-190

Dalton DL, Kotze A (2011) DNA barcoding as a tool for species identification in three forensic wildlife cases in South Africa. Forensic Sci Int 207(1):e51-e54

Eaton MJ, Meyers GL, Kolokotronis SO, Leslie MS, Martin AP, Amato G (2010) Barcoding bushmeat: molecular identification of central African and south American harvested vertebrates. Conser Genet 11:1389-1404

Ferri G, Alu M, Corradini B, Licata M, Beduschi G (2009) Species identification through DNA 'barcodes'. Genet Test Mol Biomarkers 13:421-426

Ghosh SK, Ghosh PR, Mazumder TH, Kshetrimayum M (2013) Development of species specific DNA marker as barcode sequence of greater Indian rhinoceros (Rhinoceros unicornis) from Northeast India. J Environ \& Sociobiol $10(1): 1-5$

Hebert PD, Cywinska A, Ball SL, deWaard JR (2003) Biological identifications through DNA barcodes. Proc R Soc Lond B Biol Sci 270:313-321

Hebert PD, Gregory TR (2005) The promise of DNA barcoding for taxonomy. Syst Biol 54(5):852-859

Hebert PDN, Stoeckle MY, Zemlak TS, Francis CM (2004) Identification of birds through DNA barcodes. PLoS Biol 2(10):e312
Housley DJ, Zalewski ZA, Beckett SE, Venta PJ (2006) Design factors that influence PCR amplification success of cross-species primers among 1147 mammalian primer pairs. BMC Genomics 7:253

Hsieh HM, Tsai LC, Lee JC (2011) Forensic science in support of wildlife conservation efforts-developments in genetic approaches in Taiwan. Forensic Sci Rev 23(1):19-27

Hubert N, Hanner R, Holm E, Mandrak NE, Taylor E, Burridge M et al (2008) Identifying Canadian freshwater fishes through DNA barcodes. PLoS One 3(6):e2490

lyengar A (2014) Forensic DNA analysis for animal protection and biodiversity conservation: a review. J Nat Conserv 22(3):195-205

Johnson M, Zaretskaya I, Raytselis Y, Merezhuk Y, McGinnis S, Madden TL (2008) NCBI BLAST: a better web interface. Nucleic Acids Res 36(2):W5-W9

Kumar S, Stecher G, Tamura K (2016) MEGA7: molecular evolutionary genetics analysis version 7.0 for bigger datasets. Mol Biol Evol 33(7):1870-1874

Kumar US, Ratheesh RV, Thomas G, George S (2012) Use of DNA barcoding in wildlife forensics: a study of sambar deer (Rusa Unicolor). Forest Sci and Tech 8(4):224-226

Kumar V, Neelkamal, Sharma A (2017) DNA barcoding as a wildlife forensic tool (WFT) for species identification: a case study on blackbuck (Antilope cervicapra) in India. Int J Adv Res 5(6):1283-1287

Lakra WS, Goswami M, Gopalakrishnan A (2009) Molecular identification and phylogenetic relationships of seven Indian Sciaenids (Pisces: Perciformes, Sciaenidae) based on $16 \mathrm{~S}$ rRNA and cytochrome c oxidase subunit I mitochondrial genes. Mol Biol Rep 36:831-839

Lin CS, Sun YL, Liu CY, Yang PC, Chang LC, Cheng IC, Mao SJ, Huang MC (1999) Complete nucleotide sequence of pig (Sus Scrofa) mitochondrial genome and dating evolutionary divergence within Artiodactyla. Gene 236(1):107-114

Linacre A, Tobe SS (2011) An overview to the investigative approach to species testing in wildlife forensic science. Investig Genet 2:2-9

Lorenz JG, Jackson WE, Beck JC, Hanner R (2005) The problems and promise of DNA barcodes for species diagnosis of primate biomaterials. Philos Trans $R$ Soc Lond Ser B Biol Sci 360(1462):1869-1877

Lucio CCF, Ruas EA, Rodrigues LA, Ruas PM, Vidotto T, De Souza LB, Matzenbacher $\mathrm{NI}$, Ruas CF (2011) Characterization of 12 microsatellite loci for Hypochaeris chillensis (Asteraceae) and cross-amplification in related species. Am J Bot 98(9): e262-e264

Ogden R, Dawnay N, McEwing R (2009) Wildlife DNA forensics-bridging the gap between conservation genetics and law enforcement. Endanger Species Res 9(3):179-195

Tobe SS, Linacre A (2010) DNA typing in wildlife crime: recent developments in species identification. Forensic Sci Med Pathol 6:195-206

\section{Submit your manuscript to a SpringerOpen ${ }^{\circ}$ journal and benefit from:}

- Convenient online submission

- Rigorous peer review

Open access: articles freely available online

- High visibility within the field

Retaining the copyright to your article

Submit your next manuscript at $>$ springeropen.com 